\title{
Benefits of Building Child-centered Learning Environment in Kindergarten
}

\author{
Nguyen Thi Ut Sau ${ }^{1}$, Ca Nguyen Linh Phuong², Huynh Tan Hoi ${ }^{3, *}$ \\ ${ }^{1}$ Faculty of Psychology and Pedagogy, Thai Nguyen University, Thai Nguyen Province, Vietnam \\ ${ }^{2} 19 / 5$ Kindergarten, Thai Nguyen Province, Vietnam \\ ${ }^{3}$ Department of Language, FPT University, Ho Chi Minh city, Vietnam
}

Received September 12, 2020; Revised October 21, 2020; Accepted November 29, 2020

\section{Cite This Paper in the following Citation Styles}

(a): [1] Nguyen Thi Ut Sau, Ca Nguyen Linh Phuong, Huynh Tan Hoi , "Benefits of Building Child-centered Learning Environment in Kindergarten," Universal Journal of Educational Research, Vol. 8, No. 12, pp. 6765 - 6769, 2020. DOI: 10.13189/ujer.2020.081241.

(b): Nguyen Thi Ut Sau, Ca Nguyen Linh Phuong, Huynh Tan Hoi (2020). Benefits of Building Child-centered Learning Environment in Kindergarten. Universal Journal of Educational Research, 8(12), 6765 - 6769. DOI: 10.13189/ujer.2020.081241.

Copyright $\mathrm{C} 2020$ by authors, all rights reserved. Authors agree that this article remains permanently open access under the terms of the Creative Commons Attribution License 4.0 International License

\begin{abstract}
Fundamental and comprehensive innovation is an indispensable requirement of Vietnam's education in the current period. For preschool education, one of the important contents of educational innovation is child-centered education. This is an educational perspective based on children's interests and needs in order to correctly evaluate, respect and promote each child's abilities and strengths. For the best and effective implementation of child-centered education, building a child-centered education environment in preschools is necessary and indispensable. The educational environment in a preschool is a combination of necessary physical and social conditions that directly affect child care and education. To build a child-centered educational environment is to build a physical and social environment that gives children the opportunity to learn in many different ways through play. It is an environment where the interests, needs, abilities and strengths of each child are always respected and the development of all children's potentials is promoted. This study reports the results of research demonstrates that building an educational environment from a child-centered perspective is quite important. Building a child-centered educational environment is a process of designing and using a physical environment and a psycho-social environment in organizing activities for children to create conditions for children to experience and operate abilities appropriately, preferences, suitable for each level of development of preschool children.
\end{abstract}

Keywords Child-centered Learning, Educational Environment, Development

\section{Introduction}

In the first 2 years of implementing the theme: "Building a child-centered kindergarten" for the 2016-2020 period of the Ministry of Education and Training, there are 47 public preschools in Thai Nguyen city (Vietnam) which are currently building a child-centered educational environment to meet the needs of experience, discovering and expressing themselves, promoting and creating opportunities for children to develop comprehensively and harmoniously [1].

During the 2 years of implementing the topic, many kindergartens in Thai Nguyen city such as Kindergarten 19/5 city, Quang Trung kindergarten, and Lien Co City kindergarten, etc. has been creative in creating an educational environment inside and outside the classroom such as designing a play area for children, arranging toys reasonably, conveniently, creating opportunities for all children used; innovation in child care and education activities [2].

However, in addition to the achievements, the implementation of building a "child-centered education" environment in some kindergartens in Thai Nguyen city reveals a number of limitations, both in terms of quality 
and in terms of facilities between the conditional center schools and the small off-center schools [3]. Many preschool teachers are inexperienced, so educational methods and pedagogical skills are limited. This has affected the process of building a child-centered educational environment in kindergartens in Thai Nguyen city over the past time. Stemming from that reason, we have been doing this research [2].

Building kindergartens with a child-centered perspective "is the central task of preschools to develop a comprehensive personality for preschool children [4]. Building a kindergarten from a child-centered perspective should achieve the following goals such as "to ensure all children are provided with learning opportunities through play activities in different ways", "develop children's abilities" [5]. All activities of educating children in preschools are carried out throughout and unified in order to ensure the effective and quality implementation of the preschool program and that all children benefit from the program; strengthen the renewal of the educational environment in "open" preschool institutions, stimulate the children's concentration of attention, positive thinking and emotions, and create opportunities for children to actively explore, experiment and innovate in corners with more flexibility, initiative and independence; motivating children to effectively participate in diverse play and experience activities appropriate to each locality's characteristics; Managers have improved awareness, competencies and skills in management, deeply understood and applied the concept of child-centered education in the direction and professional support for teachers. Preschool towards specific, practical, flexible, encouraging and respecting the teacher's creativity; mobilize the participation of schools, families and society, creating a unity of mutual interest in building child-centered preschools [6].

\section{Objects of Investigation and Research Methods}

To find out the current situation of building a child-centered educational environment in some kindergartens in Thai Nguyen City, we have used research methods: Questionnaire survey method, method In-depth interview, and active product research method. We have surveyed 14 management staff; 5 principals, 9 vice principals, 115 teachers at 5 public kindergartens in Thai Nguyen City including 19/5 Kindergarten, Trung Vuong
Kindergarten, Quang Trung Kindergarten, Lien Co city Kindergarten, Quang Vinh Kindergarten from the period of $2018-2019$.

The article uses both paper-based and online survey (online survey was conducted at https://surveynuts.com). Then, semi-structured in-depth interviews were also used with the support of the respondents who are management staffs or teachers. The interview transcripts were analyzed by using comparative methodology in order to find out better ideas.

When using the method of survey by questionnaire, we have designed a questionnaire consisting of 03 questions: Question 1 includes 5 items to examine the situation of building the physical environment in the classroom [7] from the point of view of child-centered accommodation (Kindergartens of Thai Nguyen City); Question 2 includes 3 items to examine the current situation of building the physical environment outside the classroom [8] at the Kindergartens of Thai Nguyen City; Question 3 consists of 4 items examining the current situation of building a psychosocial environment from a child-centered perspective in kindergartens in Thai Nguyen City.

The rating level (according to the range of points) is specified as follows: Level 1: $1.00 \leq$ Average scores $<1.75$ : Weak; Level 2: $1.75 \leq$ Average scores $<2.50$ : Fair; Level 3: $2.50 \leq$ GPA $<3.25$ : Good; Level 4: $3.25 \leq$ GPA $<4.00$ : Very good.

\section{Current Situation of Building an Educational Environment from the Point of View of Child-centered Education in Some Kindergartens in Thai Nguyen City}

\subsection{The Situation of Building the Material Environment from the Child-centered Perspective in Kindergartens of Thai Nguyen City}

The physical environment provides good opportunities for children to satisfy their operational needs and develop comprehensively physically, intellectually, aesthetically, ethically and socially. To find out about the current situation of building the physical environment from the point of view of child-centered, we have surveyed 14 managers and 115 teachers at 5 preschools in the area. The results are shown in the table 1 below: 
Table 1. Situation of building physical environment in the classroom from a child-centered perspective in kindergartens in Thai Nguyen City

\begin{tabular}{|c|c|c|c|c|c|c|}
\hline \multirow[b]{2}{*}{ Content } & \multicolumn{6}{|c|}{ Results of teacher and managers 'evaluation } \\
\hline & Very Good & Good & Fair & Weak & $\begin{array}{l}\text { Average } \\
\text { score }\end{array}$ & Grade \\
\hline $\begin{array}{l}\text { Utensils, toys, and materials are changed and added to suit the } \\
\text { child's theme / activity goals and interests. }\end{array}$ & $\begin{array}{c}10 / 115 \\
8,7 \%\end{array}$ & $\begin{array}{l}70 / 115 \\
60,9 \% \\
\end{array}$ & $\begin{array}{l}35 / 115 \\
30,4 \%\end{array}$ & 0 & 2,8 & 3 \\
\hline $\begin{array}{l}\text { Utensils, toys, raw materials and materials are kept neatly and } \\
\text { in a place where children can easily see, take, easy to use and } \\
\text { store. }\end{array}$ & $\begin{array}{l}85 / 115 \\
73,9 \%\end{array}$ & $\begin{array}{l}20 / 115 \\
17,4 \%\end{array}$ & $\begin{array}{c}10 / 115 \\
8,7 \%\end{array}$ & 0 & 3,6 & 1 \\
\hline $\begin{array}{l}\text { Having open materials (leaves, seeds, etc.), finished products, } \\
\text { unfinished products }\end{array}$ & $\begin{array}{l}12 / 115 \\
10,4 \% \\
\end{array}$ & $\begin{array}{l}40 / 115 \\
34,8 \% \\
\end{array}$ & $\begin{array}{l}60 / 115 \\
52,2 \% \\
\end{array}$ & $\begin{array}{l}3 / 115 \\
2,6 \%\end{array}$ & 2,5 & 4 \\
\hline $\begin{array}{l}\text { There are pre-bought products, homemade products for girls } \\
\text { and children, local products that are typical of regional } \\
\text { cultures (costumes, work tools, etc.) }\end{array}$ & $\begin{array}{c}15 / 115 \\
13 \%\end{array}$ & $\begin{array}{l}30 / 115 \\
26,1 \%\end{array}$ & $\begin{array}{l}60 / 115 \\
52,2 \%\end{array}$ & $\begin{array}{c}10 / 115 \\
8,7 \%\end{array}$ & 1,9 & 5 \\
\hline $\begin{array}{l}\text { Safe and hygienic materials, toys and materials that are } \\
\text { suitable for the physical and psychological aspects of } \\
\text { preschool children }\end{array}$ & $\begin{array}{l}35 / 115 \\
30,4 \%\end{array}$ & $\begin{array}{l}50 / 115 \\
43,5 \%\end{array}$ & $\begin{array}{l}30 / 115 \\
26,1 \%\end{array}$ & 0 & 3,0 & 2 \\
\hline Total scores & & & & & 2,8 & \\
\hline
\end{tabular}

Looking at the data table above, we can see that preschool teachers and administrators evaluate the construction of physical environments in the classroom from a pretty level of child-centered; however, different content is rated at different levels [9]. This is to rate the participants perception of how well they are performing each item in the table. The contents that are most appreciated are utensils, toys, materials, and materials with neat and tidy racks, in a place where children can easily see, take, use, and store; safe and hygienic materials, toys, and materials suitable for the physical and psychological aspects of preschool children. The contents that are assessed at a lower level are pre-purchased products, homemade products for girls and children, local products typical of regional cultures (costumes, labor tools, etc.); have open materials (leaves, seeds, etc.), finished products, and unfinished products. Thus, the contents that are well rated are simple ones that meet the Vietnamese educational standard of classroom facilities [10]. Content that requires richness, meticulousness, and enhancement of children's activeness is assessed at a lower level. This is also a common difficulty of many kindergartens in Thai Nguyen city because some teachers have not really made use of available materials to use in children's activities. The factor that exploits regional culture to put into children's products is limited; teachers have not exploited well cultural values to translate into toys and utensils for children. The products currently being used by the schools, created by her and the game at Thai Nguyen Kindergartens, are not particularly impressive [11].

Asked about this issue, Ms. NMT, Principal of 19/5 kindergarten said "Every year, the school launches a contest to make homemade toys, classroom decoration competitions to create a friendly environment for children. In general, the teachers participate very actively, with many beautiful products with high economic benefits [12]. However, the products are not diversified; many of them are decorative and not applicable. Many products are beautiful but easily perishable, not for long-term. This is also the concern of the teachers of the school". Ms. N.T.T, Principal of QV Kindergarten said: "The corners of the classroom are arranged neatly by the teachers, with clear corners and lots of toys [6]. However, most of them are hand-made toys; these toys are for display purpose only. The raw materials are not abundant, not showing the characteristics of the region" (Table 1).

\subsection{Current Situation of Building a Psychosocial Environment from a Child-centered Perspective at Kindergartens in Thai Nguyen City}

Psychosocial environment is understood as all social conditions such as politics, culture, relationships that help children form their own personality [13]. The social environment especially emphasized here is the communication environment in preschool, including the communication between her and the child, between children and children and between children and those around them [10].

To find out the current situation of building a psychosocial environment from a child-centered perspective, we have surveyed 14 managers and 115 teachers at 5 preschools in the area to show the results, as is shown in table 2 below. 
Table 2. Situation of building a psychosocial environment from a child-centered perspective in kindergartens in Thai Nguyen Cit

\begin{tabular}{|c|c|c|c|c|c|c|}
\hline \multirow[b]{2}{*}{ Content } & \multicolumn{6}{|c|}{ The level according to teacher and managers' assessment } \\
\hline & Very Good & Good & Fair & Weak & $\begin{array}{l}\text { Average } \\
\text { score }\end{array}$ & Grade \\
\hline $\begin{array}{l}\text { 1. Ensure a friendly, harmonious, cozy, open communication } \\
\text { environment between herself and the child, between children } \\
\text { and children, and between children and the surrounding } \\
\text { environment. }\end{array}$ & $\begin{array}{l}90 / 115 \\
78,2 \%\end{array}$ & $\begin{array}{l}25 / 115 \\
21,8 \%\end{array}$ & 0 & 0 & 3,78 & 1 \\
\hline $\begin{array}{l}\text { 2. Create conditions for children to communicate and show } \\
\text { their care for people, for objects and phenomena around them. }\end{array}$ & $\begin{array}{l}65 / 115 \\
56,5 \%\end{array}$ & $\begin{array}{l}40 / 115 \\
34,8 \%\end{array}$ & $\begin{array}{c}10 / 115 \\
8,7 \%\end{array}$ & 0 & 3,47 & 4 \\
\hline $\begin{array}{l}\text { 3. All gestures, words and deeds of teachers and adults are } \\
\text { always exemplary for children to follow }\end{array}$ & $\begin{array}{l}80 / 115 \\
69,5 \% \\
\end{array}$ & $\begin{array}{c}35 / 115 \\
30,5 \\
\end{array}$ & 0 & 0 & 3,69 & 2 \\
\hline $\begin{array}{l}\text { 4. Teachers take advantage of the relationships between } \\
\text { children to educate children and have the consistency between } \\
\text { preschool, family and social community in the care and } \\
\text { education of children. }\end{array}$ & $\begin{array}{l}75 / 115 \\
65,2 \%\end{array}$ & $\begin{array}{l}35 / 115 \\
30,4 \%\end{array}$ & $\begin{array}{l}5 / 115 \\
4,4 \%\end{array}$ & 0 & 3,6 & 3 \\
\hline Total scores & & & & & 3.63 & \\
\hline
\end{tabular}

Survey results show that preschools have done quite well in ensuring a friendly, sociable, cozy and open communication environment between teachers and the children, between children and children, between children and the environment around and all gestures, words, deeds of teachers and adults are always examples for children to follow [14]. Managers and teachers have very close assessment with reality and coincide opinions with each other. Both managers and teachers appreciate the content: "Ensuring a friendly, harmonious, cozy, open communication environment between you and your child, between children and children, between children and the environment", this content ranked 1st, followed by the content "All gestures, words and deeds of teachers and adults are always exemplary for children to follow" ranked second place [15]. However, there still exist in creating conditions let children communicate and show their care for people, for things and phenomena around them, rank 4th rank (Table 2).

According to NTQ, teacher of D1 class of 19/5 Kindergarten, "the main cause of this problem is due to the density of children in the class being too active, which hindered the coverage of the day activities". According to Ms. LTVT- Deputy Principal of Trung Vuong School, "teachers in the classroom, although they have built up daily plans from picking up and dropping off children to very specific activities during the day, sometimes they have not done it seriously [16]. The level of bargain with the child, especially during the baby picks up time". These limitations are the basis for our recommendation to develop a child-centered educational environment in kindergartens in Thai Nguyen City.

The rather essential importance for the upbringing of children has a sizable effect on parents and teachers and vice versa. The development of children's habits should soon be incorporated into the classroom with the goal of being child-centered in curriculum that features interactive classroom space in order that we can promote self-regulation and awareness as well as increase confidence and self-understanding of children [17]. The child-centered preschool experience in the curriculum provides a foundation for children's learning and is also the foundation of social development that can help children navigate success [18].

\section{Conclusions and Recommendations}

The child-centered educational method is considered a central method to help children develop their creativity and develop comprehensively through practice and experience. To apply this method, education managers and teachers are required to build an educational environment in a child-centered perspective. The educational environment includes the physical environment inside and outside the classroom and the psychological and social environment. Over the past years, many kindergartens in Thai Nguyen City have focused on building a safe, beautiful and attractive outside educational environment for children. Most schools are interested in achieving that goal, that is, the area of the school's land, the garden area and the area of supportive areas for children's outdoor activities are paid much more attention. The environment inside and outside the classroom is gradually added and created by schools to ensure cleanliness, diversity, beauty, safety, and increased excitement for preschool children. To achieve this goal, it is required that the teacher who manages the class group is always creative in taking advantage of the environment, decorating, beautifying and refreshing every day to have innovation in content for children to explore; requires managers to have a clear strategy in arranging the use of human resources, planning, organizing, directing, examining and supervising the construction of a child-centered educational environment. With good management, the school operation will proceed smoothly, contributing to the successful completion of the preschool care and education program. At the same time, parents of children need to actively coordinate schools to enhance the 
quality of building a child-centered educational environment in preschools.

\section{Ethical Clearance}

We are ensuring the quality and integrity of our research. The ideas and opinions expressed in this paper are our effort. By writing this, we surely respect the confidentiality and anonymity of our research respondents since they participated in our study voluntarily.

\section{Conflict of Interest}

No conflicts of interest noted in the paper.

\section{Source of Funding}

We would like to send our warm thanks to our workplace for financial support. The author Huynh Tan Hoi especially likes to express his thanks to Ho Chi Minh City Open University, Vietnam for financial support where he is taking a business Administration course.

\section{REFERENCES}

[1] Pereira, J. K., \& Smith-Adcock, S. Child-centered classroom management. Action in Teacher education, Vol.33, No.3, 254-264, 2011

[2] Moyer, J. The child-centered kindergarten: a position paper: Association for childhood education international. Childhood Education, Vol.77, No.3, 161-166, 2001.

[3] Tzuo, P. W. The tension between teacher control and children's freedom in a child-centered classroom: Resolving the practical dilemma through a closer look at the related theories. Early Childhood Education Journal, Vol.35, No.1, 33-39, 2007.

[4] Pianta, R., Howes, C., Burchinal, M., Bryant, D., Clifford, R., Early, D., \& Barbarin, O. Features of pre-kindergarten programs, classrooms, and teachers: Do they predict observed classroom quality and child-teacher interactions? Applied developmental science, Vol.9, No.3, 144-159, 2005.

[5] Davis, E. S., \& Pereira, J. K. Child-centered play therapy: A creative approach to culturally competent counseling. Journal of Creativity in Mental Health, Vol.9, No.2, 262-274, 2014.

[6] Shmis, T., Kotnik, J., \& Ustinova, M. Creating new learning environments: challenges for early childhood development architecture and pedagogy in Russia. Procedia-Social and
Behavioral Sciences, Vol.146, 40-46, 2014.

[7] Earthman, G. I., \& Lemasters, L. K. Teacher attitudes about classroom conditions. Journal of Educational Administration, Vol.47, No.3, 323-335, 2009.

[8] Waite, S. Teaching and learning outside the classroom: Personal values, alternative pedagogies and standards. Education Vol.3-13, 39(1), 65-82, 2011.

[9] Lenaerts, F., Braeye, S., Nguyen, T. L. H., Dang, T. A., \& Vromant, N. Supporting Teachers in Vietnam to Monitor Preschool Children's Wellbeing and Involvement in Preschool Classrooms. International Journal of Early Childhood, Vol.49, No2, 245-262, 2017.

[10] Loan, L. H., Thanh, V. T. L., \& Maternowska, M. C. Applying the child-centred and integrated framework for violence prevention: A case study on physical violence in Viet Nam. Vulnerable children and youth studies, Vol.13(sup1), 36-51, 2018.

[11] Thi Tinh, N., Linh, H., \& Hoi, H. T. Capacity for developing training program of pedagogical universities of Vietnam. International Journal of Mechanical and Production Engineering Research and Development (IJMPERD). Vol.10, No.3, 4063-4072, 2020.

[12] Rushton, S., \& Juola-Rushton, A. Classroom learning environment, brain research and the no child left behind initiative: 6 years later. Early Childhood Education Journal, Vol. 36, No. 1, 87, 2008.

[13] Ginsburg, K. R. The importance of play in promoting healthy child development and maintaining strong parent-child bonds. Pediatrics, Vol.119, No.1, 182-191, 2007.

[14] Niland, A. The power of musical play: The value of play-based, child-centered curriculum in early childhood music education. General Music Today, Vol.23, No.1, 17-21, 2009

[15] Tan, J. L., Goh, D. H. L., Ang, R. P., \& Huan, V. S. Child-centered interaction in the design of a game for social skills intervention. Computers in Entertainment (CIE), Vol.9, No1, 1-17, 2011.

[16] Reza Rachmadtullah at el. The Challenge Of Elementary School Teachers To Encounter Superior Generation In The 4.0 Industrial Revolution: Study Literature. International journal of scientific \& technology research. Vol.9, No.4, 1879-1882, 2020.

[17] Aasen, W., \& Sadownik, A. R. Does the New Kindergarten Teacher Education Program in Norway Provide Good Conditions for Professional Kindergarten Teachers? Universal Journal of Educational Research, Vol. 7(3A), 1-7, 2019.

[18] Sadownik, A. R., Aasen, W., \& Jevtic, A. V. Norwegian and Croatian Students of Undergraduate Kindergarten Teacher Education Programs on Their Professional Development and Conditions for It. Universal Journal of Educational Research, Vol. 7(3A), 8-21, 2019. 